\title{
Livro em multiformatos: $O$ espelho mágico
}

\author{
Book with multiple formats: O espelho mágico \\ Libro en múltiples formatos: $O$ espelho mágico
}

\section{Loide Leite Aragão Pinto}

Doutoranda na Universidade do Estado do Rio de Janeiro, Rio de Janeiro, Rio de Janeiro, Brasil. loide_aragao@yahoo.com.br

ORCID - https://orcid.org/0000-0003-2176-6948

\section{Miryam Bonadiu Pelosi}

Professora doutora na Universidade Federal do Rio de Janeiro, Rio de Janeiro, Rio de Janeiro, Brasil. miryampelosi@ufrj.br

ORCID - https://orcid.org/0000-0002-6109-4296

Recebido em 02 de setembro de 2020

Aprovado em 16 de novembro de 2020

Publicado em 21 de dezembro de 2020

\section{RESUMO}

O objetivo desse trabalho é apresentar o percurso de criação da obra literária acessível $O$ espelho mágico e trazer elementos que fundamentam a produção acessível de um livro em multiformatos. Diante dos postulados teóricos e legais, que versam sobre os direitos da pessoa com deficiência, discute-se um pouco a luta pela afirmação de direitos da pessoa com deficiência e seu papel de protagonista nos processos sociais de tomadas de decisões. $\mathrm{Na}$ metodologia, apresentam-se os diferentes formatos do livro e os caminhos para a produção de cada um deles. A partir dos instrumentos teóricos e legais que versam sobre acessibilidade, descreve-se como os diferentes formatos do livro foram estruturados, de modo a possibilitar a fruição estética da obra e o ato comunicacional do texto pelo maior número de pessoas possível dentro da perspectiva do Desenho Universal. Ao final, ressalta-se a importância da produção de livros em multiformatos e da consultoria para a produção de material acessível.

Palavras-chave: Acessibilidade; livro em multiformatos; Desenho Universal.

\section{ABSTRACT}

The objective of this work is to present the process of creation of the accessible literary work O espelho mágico and bring some elements that underlie the accessible production of a book with multiple formats. In face of theoretical and legal postulates it discusses about the rights of persons with disabilities and the relevance of their participation in the decision making processes. In the methodology, it shows the different formats of the book and the ways of production of all of them. By the theoretical and legal postulates that focus on the accessible actions, it is described how the formats were structured to enable the aesthetic enjoyment of the book and its communication process for a large number of people in the perspective of Universal Design. It concludes that produces a book with multiple formats is 
http://dx.doi.org/10.5902/1984686X54666

very important for all the people, especially people with disability, and that the consulting is an important key in this process.

Keywords: Accessibility; book with multiple formats; Universal Design.

\section{RESUMEN}

El objetivo de este trabajo es presentar el camino de creación de la obra literaria accesible O espelho mágico y aportar elementos que apoyen la producción accesible de un libro en múltiples formatos. A la vista de los postulados teóricos y legales, que abordan los derechos de las personas con discapacidad, Se discute un poco la lucha por la afirmación de los derechos de las personas con discapacidad y su rol como protagonista en los procesos de toma de decisiones sociales. En la metodología se presentan los diferentes formatos del libro y los caminos para la producción de cada uno. A partir de los instrumentos teóricos y legales que abordan la accesibilidad, se describe cómo se estructuraron los diferentes formatos del libro, con el fin de posibilitar el disfrute estético de la obra y el acto comunicativo del texto por parte de tantas personas como sea posible dentro de la perspectiva del Diseño Universal. Se concluye que producir uno libro con múltiples formatos es muy importante para todas las personas, especialmente las personas con discapacidad, y que la consultoría es una clave importante en este proceso.

Palabras clave: Accesibilidad; libro con múltiples formatos; Diseño Universal.

\section{Introdução}

A literatura, por meio de sua narrativa, alcançou pessoas a partir da oralidade e do texto escrito. Esses formatos permitiam a leitores e ouvintes conhecerem a arte da palavra e a magia dos contos, causos e novelas. Todavia, esses formatos ofereciam obstáculos às pessoas com necessidades específicas em relação à visão, à audição, à cognição, à interpretação e ao manuseio, que deixavam de fora um gama de pessoas e, dentre elas, as pessoas com deficiência. Do formato que as letras ganham no papel até o ruído do som quando as palavras são pronunciadas, passando pelo folhear das páginas, observam-se barreiras que impedem muitas pessoas de acessar o texto literário.

Desse modo, percebe-se que é preciso ultrapassar as barreiras estéticas e atitudinais presentes nesses formatos e eliminar os problemas que impossibilitam a fruição da obra por diferentes pessoas. É fundamental compreender que a deficiência de uma pessoa não a torna incapaz de acessar uma obra literária, mas sim o formato em que essa obra se apresenta. Um meio deficiente pode impossibilitar o "acesso de forma plena" (LEITE, 2012, p. 51) e, dessa forma, não proporcionar a "equiparação de oportunidades" (ibidem).

O conceito de livro acessível alcança dimensões de materiais em formato acessível e multiformato. Sendo assim, livro acessível vem a ser o material literário produzido de forma 
http://dx.doi.org/10.5902/1984686X54666

que seu conteúdo e sua forma sejam disponibilizados em variados formatos de modo a possibilitar que pessoas com necessidades específicas possam acessá-lo sem qualquer entrave ou obstáculo que venham a dificultar ou impossibilitar o recebimento da mensagem e da expressão artística (PINTO, 2019, p. 30).

No Censo de 2010, um percentual de 23,9\% da população brasileira declarou ter algum grau de dificuldade em pelo menos uma das habilidades investigadas (IBGE, 2012). Contudo, a parcela da população que possuía grande ou total dificuldade de enxergar, ouvir, caminhar ou subir escadas correspondeu a 6,7\%. Assim, o Brasil tinha uma proporção de deficientes visuais de 3,4\%, deficientes motores de 2,3\%, deficientes auditivos de $1,1 \%$, aos quais se somaram as pessoas com deficiência mental/intelectual com um total de 1,4\% (IBGE EDUCA, 2020).

Logo, é preciso que se elabore projetos e diretrizes que levem a produtos e espaços acessíveis como um todo e que alcancem a todos. A Lei Brasileira de Inclusão (BRASIL, 2015) exorta a questão da acessibilidade, entendendo que ela é a possibilidade e condição de alcance para utilização de todo e qualquer produto e espaço, com segurança e autonomia (BRASIL, 2015, Art. 3ํinciso I). Dessa forma, há a necessidade de se eliminar as barreiras presentes nos diferentes espaços culturais e produtos, visto que essas barreiras podem ser quaisquer entraves, obstáculos ou comportamento que limitem ou impeçam qualquer pessoa de usufruir com segurança um bem cultural (BRASIL, 2015, inciso IV). As barreiras podem ser tanto urbanísticas, quanto atitudinais e acontecem quando algum elemento ou comportamento bloqueie ou prejudique a participação social da pessoa com deficiência em igualdade de condições e oportunidades com as demais pessoas.

$\mathrm{Na}$ literatura, principalmente na literatura infantil e juvenil, a produção de livros caminha em parceria com a produção de imagens. Produzir, nesse campo de atuação, livros acessíveis é uma conquista da e para as pessoas com deficiência. No documento $A$ consolidação da inclusão escolar no Brasil de 2003 a 2016 (BRASIL, 2016), a ideia de livro acessível está relacionada à concepção de livros em formatos acessíveis (ibidem). De acordo com a ABNT - 15599/2008, as obras literárias em geral, para fruição do público, devem estar dispostas nas bibliotecas e espaços culturais em meios sonoro e visual, ou em quaisquer outros suportes, como ampliação de tela, leitura de tela, sintetizador de voz, display Braille, thermoform, impressão Braille e linha Braille. Também poderão ser disponibilizados scanner, com sistema para reconhecimento ótico de caracteres, e outros 
http://dx.doi.org/10.5902/1984686X54666

dispositivos facilitadores e adaptados para pessoa com deficiência, como obras da literatura interpretadas em LIBRAS (ABNT, 2008).

Para a criação e recriação das obras literárias, duas áreas de conhecimento são fundamentais: o Desenho Universal e a Tecnologia Assistiva. A primeira foca na "[...] concepção de produtos, ambientes, programas e serviços a serem usados por todas as pessoas, sem necessidade de adaptação ou de projeto específico, incluindo os recursos de tecnologia assistiva." (BRASIL, 2015, Art. $3^{\circ}$, inciso II). A segunda engloba:

[...] produtos, equipamentos, dispositivos, recursos, metodologias, estratégias, práticas e serviços que objetivem promover a funcionalidade, relacionada à atividade e à participação da pessoa com deficiência ou com mobilidade reduzida, visando à sua autonomia, independência, qualidade de vida e inclusão social (BRASIL, 2015, Art. 3ํㅡ, inciso III).

A produção de material, dentro dessa perspectiva do Desenho Universal, ensina que não basta fazer algo atraente para um público e, nesse percurso, criar barreiras para outros grupos, é preciso criar materiais integrados que, em distintos formatos, tragam consigo um pouco da magia da história. Daí a necessidade de se produzir um trabalho em diálogo da autora com o ilustrador, do ilustrador com a autora, da autora com os consultores e dos consultores com a autora.

Discutir a importância do envolvimento das pessoas com deficiência nos materiais e produtos pensados para esse diverso público sai do âmbito do favorecimento e vai para o âmbito de reconhecimento de suas vozes e vontades. Com isso, a nova postura, diante da criação de políticas e projetos, deve ser a de colocar as pessoas com deficiência como protagonistas no processo de tomadas de decisões (AMARANTE; LIMA, 2009), não apenas dando voz às pessoas com deficiência, mas reconhecendo o valor dessa voz. Assim, ressalta-se a importância da atuação direta das pessoas com deficiência na consultoria de espetáculos artísticos e demais obras artísticas voltadas para o público, uma vez que ninguém melhor do que a pessoa com deficiência para avaliar e fazer considerações sobre o material artístico, organização, comunicabilidade e acessibilidade propostos para ela.

O objetivo desse artigo é apresentar os caminhos de produção do livro acessível $O$ espelho mágico e seus dez formatos acessíveis, que buscam eliminar as barreiras presentes no convencional livro em tinta. 
http://dx.doi.org/10.5902/1984686X54666

\section{Método}

Trata-se de uma pesquisa descritiva, qualitativa, do tipo relato de experiência, que apresenta o livro $O$ espelho mágico e suas adaptações, os formatos realizados, as consultorias e o local de hospedagem dos formatos digitais.

O conto $\mathrm{O}$ espelho mágico faz parte do repertório de histórias da contadora de histórias Loide Aragão, desde 2006. O conto traz a história da jovem princesa Gymgya e de seu espelho mágico. A princesa se vê obrigada a casar, mas coloca o desafio para seus pretendentes de somente se casar com quem conseguisse se esconder do seu espelho. Um dos pretendentes, Rodrigão, um herói que merece a gratidão dos animais, perde três vezes o desafio, porém se transforma em inseto e consegue vencê-lo (CASCUDO, 2004).

A obra foi adaptada em 10 formatos: 1) livro em tinta; 2) livro em imagens; 3) moldes e fantoches; 4) texto simplificado; 5) fonte ampliada; 6) audiolivro; 7) audiolivro com audiodescrição; 8) vídeo em Libras; 9) livro em TXT para leitor de tela; 10) Braille para impressão.

Os formatos acessíveis do livro em arquivo digital estão hospedados em um endereço eletrônico (PINTO, 2019b). O tempo de produção da obra e de seus diferentes formatos foi de um ano. A adaptação da obra compreendeu quatorze etapas, que dialogavam entre si:

1 - Transposição da versão oral para o texto escrito;

2 - Envio do texto escrito para o ilustrador criar os personagens e as ilustrações;

3 - Consultoria com especialistas sobre nome dos personagens, simplicidade do traçado das ilustrações e texturas;

4 - Elaboração do texto simples com pictogramas;

5 - Gravação do audiolivro;

6 - Elaboração da versão em tinta do livro;

7 - Produção do livro em imagem;

8 - Produção do livro em Libras;

9 - Produção dos fantoches e materiais de comunicação alternativa;

10 - Produção do texto simplificado;

11 - Produção das audiodescrições;

12 - Produção do audiolivro com audiodescrição;

13 - Produção do arquivo digital em TXT para leitor de tela;

14 - Produção do arquivo digital em TXT do livro para impressão em Braille. 
http://dx.doi.org/10.5902/1984686X54666

\section{Resultados}

Os resultados são apresentados em dez subitens que compreenderam os dez formatos do livro.

\section{Livro em tinta}

A primeira etapa da produção do livro foi a transposição da versão oral da autora para o texto escrito, buscando preservar as características dramáticas e a alegria do conto. Para essa versão acessível, foram alterados os nomes dos personagens e acrescentadas características especificas étnico-raciais das matrizes africana e indígena aos personagens Gimgya e Rodrigão. Foi realizada a modificação nos personagens e encaminharam-se ao ilustrador as orientações para o desenho. Nas Figuras a seguir, apresentam-se a princesa Gimbya e o índio Rodrigão.

Figura 1 - Desenho da princesa

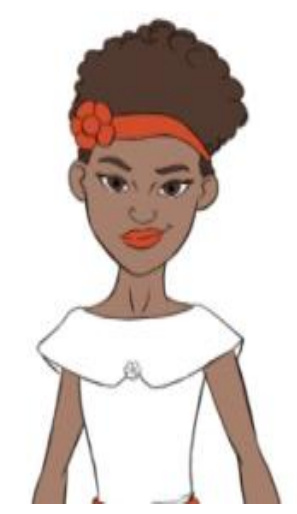

Audiodescrição: Uma jovem negra com curtos cabelos pretos, encaracolados e volumosos. Ela tem faixa vermelha na testa com uma florzinha do lado esquerdo. Olhos grandes amendoados e sobrancelhas finas levemente arqueadas. Lábios vermelhos com sorriso cerrado. O pescoço longo segue até a blusa branca de gola caída com uma pequena florzinha vermelha ao centro e cinto vermelho. Os braços estão estendidos.

Fonte: PINTO, 2019a. 
http://dx.doi.org/10.5902/1984686X54666

Figura 2 - Desenho do Rodrigão

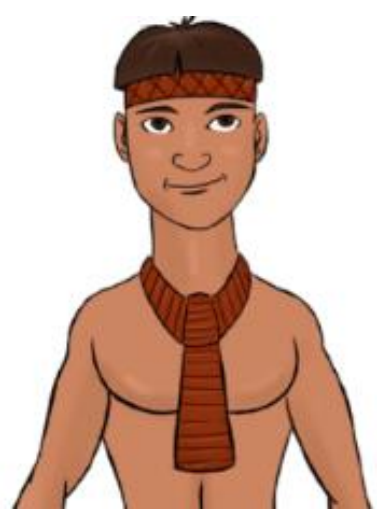

Audiodescrição: Um jovem moreno de cabelos pretos lisos, com uma faixa de fibras marrons na testa. Sobrancelhas escuras e olhos negros puxados. Lábios finos e cerrados. Colar grosso de fibras marrons no pescoço com tira caída no peito. Os braços estão estendidos.

Fonte: PINTO, 2019a.

Após essa etapa de escrita, passou-se para a elaboração do texto simples com símbolo, que foi feito a partir da escrita do conto. Duas tabelas, com uma linha cada, traziam um resumo da página, associando texto com símbolos e pictogramas correspondentes. $\mathrm{O}$ material foi enviado ao ilustrador para elaboração das ilustrações. Cada página foi composta por uma parte do conto, uma ilustração e dois textos simples com símbolos.

Ao final de cada página foi inserida uma linha de comunicação alternativa para possibilitar que ouvintes ou leitores com dificuldades de comunicação e interação pudessem interagir com a leitura do conto. Por meio da comunicação alternativa, esperavase que as pessoas com necessidades específicas na comunicação pudessem indicar se gostariam de voltar à página anterior, repetir a leitura, parar ou avançar com o texto.

Cada página do livro foi elaborada em arquivo separado de editor de texto para permitir que as páginas tivessem cores diferentes. O livro contou com vinte páginas de histórias, seguindo o modelo da página 7, apresentado na figura a seguir: 
http://dx.doi.org/10.5902/1984686X54666

Figura 3 - Página 7 do livro 0 espelho mágico

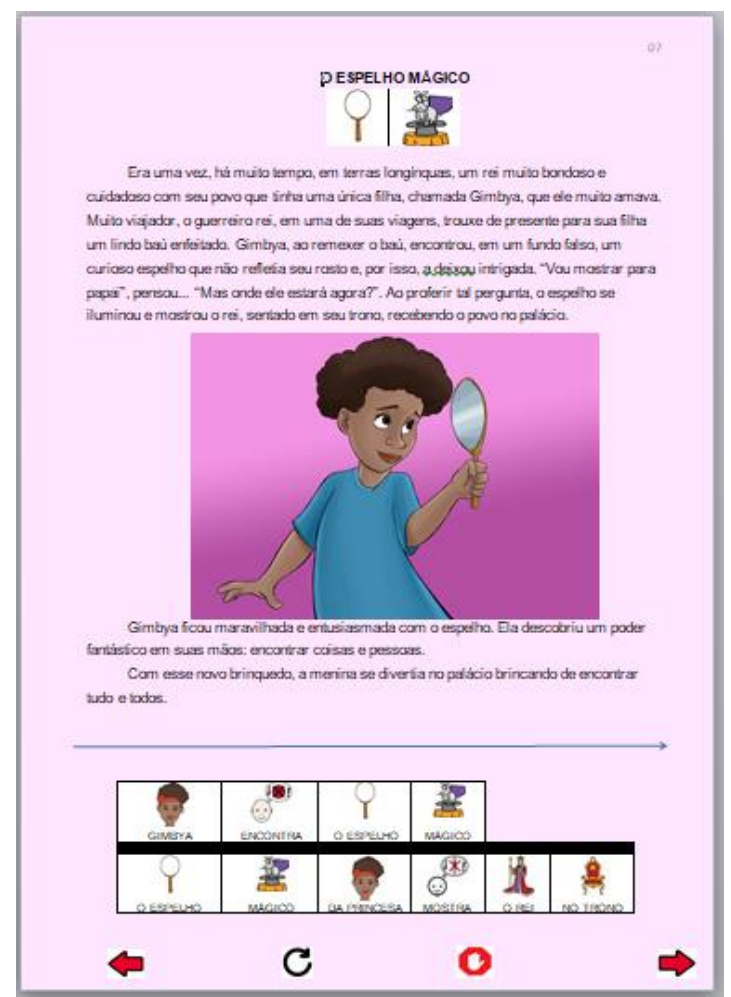

Audiodescrição: Na parte superior central, sobre um fundo rosa, O espelho Mágico com duas figuras pequenas abaixo, sendo uma de um espelho e outra de mão tirando um coelho da cartola. Primeiro parágrafo do conto em fonte preta formato Arial, com espaçamento 1,5 e alinhado à esquerda. Ilustração da menina princesa. Abaixo, segundo parágrafo do conto. Mais abaixo, na parte inferior central, fina seta alongada marca uma linha azul na horizontal. Na parte debaixo da seta, pequena tabela traz duas frases com texto simplificado com símbolos. No final da página, linha de comunicação alternativa, recurso que permite diálogo e interação da história com ouvintes com impedimento de fala.

Fonte: PINTO, 2019a.

$\mathrm{Na}$ página 27 do livro, encontram-se nove códigos de barras, que levam aos endereços do sítio eletrônico onde estão depositados os demais formatos em arquivo digital do livro. Os endereços eletrônicos por $Q R$ code podem ser lidos facilmente pelas pessoas usando um celular com câmera fotográfica e o aplicativo de leitura de $Q R$ code apropriado, que faça a conversão da informação (KLIX, 2015).

\section{Livro em imagens}

Este recurso foi pensado para dar foco à arte da ilustração. Trata-se de uma forma de organização da informação que exige uma interação e capacidade de leitura de imagens, sequência de ação e criação. Durante a contação de história, as ilustrações de um livro sempre agradam ao público infantojuvenil, uma vez que o foco não está na leitura do texto, mas nas imagens que vão surgindo e complementando a narrativa. 
http://dx.doi.org/10.5902/1984686X54666

É um recurso bom para adaptação do tempo da história que poderá ser mais lento ou mais rápido, de acordo com o tempo de atenção do público. Desse modo, pode-se resumir o conto ou ir acrescentando elementos da narrativa conforme a interação do ouvinte. É uma técnica muito boa para usar com crianças dispersas, que ouvem a história enquanto interagem com outros elementos.

A partir do livro em imagem, optou-se pela aplicação de relevo sobre as ilustrações para permitir que pessoas com baixa visão ou cegas pudessem conhecer a ilustração a partir da percepção tátil. Esta etapa, concomitante ao desenvolvimento dos demais formatos acessíveis, passou por consultoria de uma pessoa cega para apreciação e avaliação do material.

\section{Moldes e fantoches}

Este formato buscou a interação com o público transpondo as ilustrações para bonecos manipuláveis de tecido e papel. Foram feitos dois bonecos bidimensionais grandes da princesa Gimbya e do Rodrigão, tendo como base a ilustração do livro. Outros dois pequenos bonecos da princesa e do Rodrigão foram produzidos a partir da adaptação de brinquedos infantis como os bonecos de manipulação. As roupas, o cabelo e os acessórios originais dos bonecos foram retirados e novos materiais foram agregados para que esses brinquedos representassem as personagens Gimbya e Rodrigão. Desse modo, novos cabelos foram montados e colados, roupas e acessórios ganharam novos tons e foram costurados para compor a vestimenta dos personagens.

O espelho e as figuras, impressas em papel fotográfico e coladas em folha imantada, permitiram a troca das imagens, de acordo com a sequência da história. Com esse efeito, o público pode se surpreender com a troca da imagem e entender melhor o que o espelho mostra para a princesa. Para ilustrar o conto usando o espelho com foco da narrativa, foram usadas três ilustrações do reflexo do espelho presentes no conto: do cozinheiro, do Rodrigão na gruta e do Rodrigão com as harpias. Outras duas ilustrações do livro foram adaptadas para o formato de reflexo do espelho: a do guerreiro e a do Rodrigão dentro da baleia. Como na narrativa o espelho encontra mais dois personagens, o rei, pai da princesa, e a costureira, solicitou-se ao ilustrador que fizesse a ilustração desses personagens no reflexo do espelho de modo a integrar as ilustrações desses personagens à contação de histórias. 
http://dx.doi.org/10.5902/1984686X54666

Por fim, como material complementar e interativo de criação, foi solicitado ao ilustrador que fizesse os personagens da Princesa e do Rodrigão em fantoches dobráveis de papel. Esse material tanto poderá ser texturizado e compor o material em relevo do livro, quanto servir de material complementar de apoio e criação da história com o público.

\section{Texto simplificado}

Outra proposta de adequação da linguagem foi feita em relação à leitura da história. O texto corrido da história com elementos de coesão e referência exigem do leitor capacidade de retomada de termos outrora mencionados, bem como dos tempos e lugares.

De modo a facilitar a leitura, elaborou-se uma forma de texto que, fragmentada em períodos mais simples, apresentasse a história de forma mais clara e objetiva. $O$ recurso do texto simplificado consiste em produzir uma sentença na ordem direta da oração, com indicação do sujeito, seu estado ou ação, e complementos necessários, como por exemplo: "O rei tinha uma filha." Esse tipo de texto simples é mais acessível para as pessoas em fase de letramento ou necessidades específicas. Assim, a opção de simplificar o texto teve o objetivo de tornar o conteúdo da história acessível para públicos com essas especificidades.

\section{Fonte ampliada}

O formato em fonte ampliada foi produzido com o objetivo de fornecer uma versão do livro com uma fonte de letra e ilustrações ampliadas. Buscou-se, na reconfiguração do texto e das imagens, manter o alinhamento com o livro físico, para que a pessoa com baixa visão pudesse fazer uma leitura mais fácil do texto e visualizasse melhor letras e imagens.

O material foi organizado em folha tamanho $\mathrm{A} 4$, com orientação em paisagem. Foram aplicados à folha fundo preto e letra branca. A fonte utilizada foi sem serifa, Arial 24, as letras também ficaram em maiúscula. O espaçamento entre linhas foi duplo e as margens com formatação moderada com 2,54 cm de margens superiores e inferiores e 1,9 cm de margens direita e esquerda. As ilustrações foram ampliadas para ocupar quase toda a dimensão da folha.

\section{Audiolivro}

Ao longo do processo de criação das imagens, foi feita a gravação do áudio para produção do audiolivro. Ele foi produzido em formato de contação de histórias, buscando dar um ritmo mais alegre e divertido à história. A gravação foi feita por páginas, depois recortadas e montadas em um único áudio. Para edição foram usados os softwares livres 
Wavosaur (2020) e o Audacity (2020). O primeiro software oferecia uma ferramenta mais simples para corte e colagem das partes do texto, bem como montagem da faixa. $\mathrm{O}$ segundo software oferecia ferramentas mais fáceis de conversão do áudio de mono para estéreo e formato wave.

Foi feito um roteiro para produção de um áudio introdutório, apresentando o audiolivro como elemento constitutivo do livro acessível $\mathrm{O}$ espelho mágico. Em seguida, as demais partes do roteiro focaram na parte textual da narrativa do livro, ficando excluídos os elementos pré e pós-textuais. Depois de capturado o áudio das páginas, deu-se o processo de edição do áudio para criar um único arquivo com a narração da história. As ferramentas mais utilizadas foram de corte, cola e captura dos áudios. Toda essa edição foi feita no Wavosaur. Depois de finalizada essa etapa de montagem, o áudio foi trabalhado no programa Audacity para finalização do formato wave e estéreo. $O$ áudio ao final ficou com a duração de 23 minutos com o nome de Audiolivro.

\title{
Audiolivro com audiodescrição
}

Este formato tem como base a mesma narração da obra feita pela contadora de histórias para o formato do livro em audiolivro. Nessa versão, no entanto, as páginas estão organizadas por faixa, tendo cada faixa a audiodescrição da ilustração da página. São ao todo 22 faixas: a primeira de apresentação, a segunda da capa e as demais das páginas do livro. Na sequência, é apresentada a audiodescrição Rodrigão e as formigas:

\begin{abstract}
AUDIODESCRIÇÃO: formigas com patas levantadas sobre duas folhas grandes olham para Rodrigão, que segura uma pedra. Ao fundo, sombras esverdeadas de coqueiros sob um céu azul. À frente, parte do caule bege de um coqueiro está no canto esquerdo. Na folha de cima, há duas formigas e, na de baixo, uma formiga. Elas estão com as antenas levantadas, olhos negros e sorriso cerrado. As patas dianteiras estão erguidas e as quatro patas inferiores apoiadas. Rodrigão, ao lado direito, olha para as formigas com um sorriso aberto. Nas mãos, ele segura uma pedra cinza grande à frente do corpo. Fim da audiodescrição (PINTO, 2019b, p. 13).
\end{abstract}

As audiodescrições foram gravadas e, depois, editadas para serem fixadas nos respectivos áudios das páginas com a ilustração. Depois de feita a edição, o áudio foi exportado para wave para aplicação de faixa estéreo e informações da obra. Uma playlist foi montada para agrupar todas as faixas do livro com audiodescrição.

\section{Videolivro em Libras}

Para o videolivro em Libras, foram utilizados, como base para o roteiro, os áudios produzidos para o audiolivro. A única modificação feita no texto foi em relação à 
apresentação do material e sua relação com a obra $O$ espelho mágico. Foram montadas vinte e três cenas: a abertura do vídeo com uma imagem de dois segundos da capa do livro O espelho mágico; depois uma cena de curta duração apresentando o videolivro; e, na sequência, iniciou-se a narração da história com os áudios do audiolivro ao fundo e o intérprete tradutor em destaque do lado direito da cena, com a ilustração do lado esquerdo. A legenda corre na parte de baixo da tela.

Toda a edição foi feita pelo Coletivo de Pesquisa em Cinema Ambiental (CUCA, 2020), que disponibilizou um editor da equipe do coletivo para edição e montagem do vídeo. $A$ equipe disponibilizou o espaço e os equipamentos necessários à edição do vídeo e utilizou um programa de edição copyright para editar e exportar o vídeo. A produção foi da autora do livro, bem como a elaboração dos roteiros e montagem dos cenários.

O vídeo foi montado com quadros que se sobrepunham na tela com a imagem de fundo do cenário, a legenda, o áudio e o vídeo do tradutor. Foram aplicados efeitos de transição de cena, simulando o virar de página do livro.

\section{Formato TXT para leitor de tela}

O livro em formato TXT para leitor de tela foi uma sugestão do consultor cego. Esse formato simples de edição de texto permite que os leitores de telas circulem melhor por um texto com poucos elementos marginais de leitura. Para os deficientes visuais, a tecnologia tem fornecido softwares cada vez mais sofisticados para leitura de tela, letras, símbolos e imagens.

A produção do formato em TXT teve como objetivo fornecer todas as informações pré e pós-textuais do livro, ao trazer a organização em texto desses elementos. O material possibilitou que o deficiente visual tivesse acesso não só à história, mas também à organização do livro. Toda a informação textual do livro foi colocada no formato TXT, bem como a versão em audiodescrição das ilustrações.

Trazer os elementos de audiodescrição para o formato TXT teve como objetivo permitir que o deficiente visual, usuário de leitores de tela, tivesse acesso às ilustrações a partir da técnica de audiodescrição.

\section{Braille para impressão}

O formato em Braille para impressão teve como base o arquivo TXT organizado. Ele foi separado por outro ordenamento de páginas para impressão usando o software Braille 
Fácil. O texto tanto pode ser digitado diretamente no Braille Fácil, como pode ser importado a partir de um editor simples de texto. Optou-se por criar um arquivo TXT e importá-lo para o programa, com um recurso simples de selecionar, copiar e colar o texto no software Braille Fácil (UFRJ, 2020).

Também foi prevista a inserção de uma página para a audiodescrição da imagem, seguida de uma página para inserção da textura em relevo da ilustração correspondente. Essa organização buscou fornecer uma contextualização da ilustração, para depois apresentar a imagem em relevo. $\mathrm{O}$ arquivo digital foi salvo em formato TXT.

\section{Discussão}

A produção de um livro acessível, mais do que um ato de boa vontade, é um elemento tecnológico que requer múltiplos conhecimentos sobre Desenho Universal (NUNES; MADUREIRA, 2015), Tecnologia Assistiva e legislação específica sobre o tema. Além disso, há a necessidade do conhecimento e do uso de diferentes ferramentas para produção dos formatos desejados para o texto.

Na elaboração dos formatos acessíveis do livro O espelho mágico, as adaptações dos diferentes formatos tiveram como base o livro em tinta. Ou seja, o livro em tinta foi a base para todos os demais formatos acessíveis da obra. Desde o início, o projeto de criação previa um trabalho integrado de produção do livro em tinta com os demais formatos acessíveis. Logo, o desafio foi produzir um bom material integrado, que fugisse da produção de formatos acessíveis que fossem arremedos de acessibilidade. O que se queria era um material integrado de composição artística.

Todos os formatos juntos formam a unidade do livro O espelho mágico, cuja trajetória de produção exigiu muita capacidade de projeção e reformulação das etapas de elaboração, pois, em alguns momentos, foi preciso voltar mais de uma etapa para reformular o texto ou as imagens, uma vez que a adaptação de um elemento impactava no projeto como um todo. Um bom exemplo disso foi o trabalho com a ilustração, que procurou seguir os princípios do Desenho Universal (CONNELL et al, 1997) de produção de um material atraente para todos e acessível para o maior número possível de pessoas.

Seguindo a premissa do Desenho Universal, procurou-se a produção de uma ilustração em equilíbrio na relação entre personagens e fundos de imagem, de modo que, na elaboração do material em relevo, a leitura tátil não fosse prejudicada. Partindo desse princípio, algumas alterações foram feitas ao longo do processo de produção para alcançar 
um maior equilíbrio e distinção das imagens. Cada alteração precisou considerar os efeitos que essa mudança traria para os demais formatos e necessidades específicas.

As texturas das imagens, para a adaptação da história, foram confeccionadas em relevo, tendo como apoio o material Guia prático para adaptação em relevo, da Secretaria de Estado da Educação de Santa Catarina (SANTA CATARINA, 2011), cujo objetivo é orientar educadores para aplicação de relevo, em especial para apreciação do público com deficiência visual. A deficiência visual pode se apresentar com a cegueira, que é uma alteração grave ou total de uma ou mais das funções elementares da visão. Ela pode afetar de modo irremediável a capacidade de perceber cor, tamanho, distância, forma, posição ou movimento em um campo mais ou menos abrangente (SÁ; CAMPOS; SILVA, 2007).

Conforme se pontuou no início do texto, as quatorze etapas de elaboração da obra ocorreram em diálogo, pois passaram por consultoria e avaliação de seus formatos ao longo dos processos, para que um formato não prejudicasse a produção ou o entendimento de outro. Sendo assim, a etapa de transposição da versão oral para o texto escrito só findou após a gravação do audiolivro.

A elaboração das ilustrações ocorreu ao mesmo tempo em que foram produzidos o livro em imagem, com opção para ilustração em relevo, e os materiais para comunicação alternativa. A necessidade de compreensão de um formato modificava outro e exigia reelaboração.

Outro desafio foi a produção de ilustrações que permitissem bom contraste e posteriores aplicações de textura com boa distinção dos elementos. Um bom exemplo foi a ilustração de Rodrigão com as formigas. De início a imagem trazia seis formigas sobrepostas e muito juntas umas das outras, em cima de uma folha. Apesar das críticas iniciais quanto à sobreposição de imagens, a imagem só passou por reformulações após a produção da ilustração em relevo e avaliação do consultor. Esse pontuou a impossibilidade de se entender a imagem por conta da confusão causada pela aproximação dos elementos, que poderia ser uma barreira para as pessoas com baixa visão, pois essas têm restrição quanto à quantidade de dados visuais que recebem do ambiente "para a construção do conhecimento sobre o mundo exterior. Em outras palavras, o indivíduo pode ter um conhecimento restrito do que o rodeia" (SÁ; CAMPOS; SILVA, 2007, p. 17).

Essa avaliação fez com que fosse solicitado ao ilustrador que reorganizasse as formigas na imagem de modo a favorecer a aplicação de uma textura em relevo mais clara. A escolha de cada um dos materiais para a aplicação de textura em relevo procurou seguir 
um padrão de memória sensorial na identificação das imagens para o toque. Trabalhar essa memória tátil foi importante, pois, na passagem de sondagem tátil de uma ilustração para a outra, a memória ajudaria no reconhecimento dos personagens. O consultor destacou a importância do uso dessa técnica na apreciação da obra como um todo.

Os últimos formatos a serem finalizados foram os arquivos em TXT para leitor de tela e para impressão em Braille, bem como o texto simplificado. Os dois primeiros dependiam da finalização das imagens e produção das audiodescrições. O terceiro precisava de uma compreensão de todos os formatos e possibilidades da história que levassem a uma simplificação sem prejuízo da narrativa, uma vez que, apesar de ser um conto pequeno, sua narrativa era repleta de acontecimentos, personagens e cenários.

Esse tipo de adaptação do texto complexo para o texto simplificado faz-se necessário, pois a complexidade e as tramas de um texto exigem do leitor uma sequência rápida da leitura e retomada de ações. Perceber a coerência do texto é ser capaz de ligar os elementos, formando sequências veiculadoras de sentido $(\mathrm{KOCH}, 2010)$. Nem sempre essa habilidade está presente em todos os leitores, ora por estarem em processo de letramento, ora por apresentarem necessidades específicas que impedem esse tipo de leitura mais corrida, com retomada de elementos, tempos e lugares, com capacidade de inferir elementos a partir do universo textual $(\mathrm{KOCH}, 2007)$.

Silva e Finatto (2018) pontuam que a produção do texto simples precisa torná-lo mais acessível para diferentes públicos e não apenas para pessoas leigas no assunto proposto. Desse modo, os autores orientam para que se:

Conheça o público para o qual irá escrever: delimite o público, entenda suas limitações e considere o grau de instrução desse público. Evite palavras rebuscadas que só sirvam para "melhorar" o estilo do seu texto. Mantenha, sempre que possível, a ordem canônica - a mais comum/direta - da língua portuguesa (sujeito, verbo, objeto) em suas frases (SILVA; FINATTO, 2018, p. 15-16).

Conforme pontuando mais acima, a produção da audiodescrição das imagens foi uma das últimas etapas, pois dependia da finalização das ilustrações, da habilidade da autora na produção do texto audiodescritivo e da consultoria de pessoas cegas para ser finalizada. A técnica de audiodescrição consiste na "[...] transformação de imagens em palavras para que informações-chave transmitidas visualmente não passem despercebidas e possam também ser acessadas por pessoas cegas ou com baixa visão" (FRANCO; SILVA, 2009, p. 20). 
http://dx.doi.org/10.5902/1984686X54666

Produzir uma audiodescrição requer dedicação, treino, sensibilidade, técnica e, principalmente, consultoria de pessoas cegas. Lima (2011) observa que, para a produção de um roteiro de audiodescrição, deve-se privilegiar elementos de concisão, clareza, correção, especificidade e vividez. Desse modo, espera-se um texto com o mínimo de palavras, com o máximo de informações possível, nítido, exato na descrição do evento visual, preciso, além de vívido na elucidação da imagem.

Após a produção do texto da audiodescrição, foi possível finalizar o arquivo em formato TXT para leitor de tela e para impressão em impressora Braille. Segundo Borges (1997), os deficientes visuais foram beneficiados com a tecnologia, em especial de computação, pois seus aparatos, como computadores, scanners, impressoras, permitem ao cego a possibilidade de escrever, ser lido e ler o que os outros escreveram a partir de projeto como o DOSVOX.

No site do Projeto DOSVOX (UFRJ, 2020), tem-se acesso ao programa e sua história de criação. Desenvolvido pelo Núcleo de Computação Eletrônica da Universidade Federal do Rio de Janeiro (UFRJ), o sistema operacional DOSVOX permite que pessoas cegas utilizem um microcomputador comum (PC) para desempenhar uma série de tarefas, adquirindo assim um nível de independência no estudo e no trabalho a partir da leitura em voz sintetizada da tela do computador.

Para o arquivo em formato TXT para impressão em Braille, foram necessários o uso de ferramentas e conhecimento do código Braille de escrita (BRASIL, 2018a; 2018b). Esse código foi criado por Luiz Braille, a partir de sua experiência de trabalho com o sistema informacional de sonografia. Os toques dos sinais sonoros foram adaptados para pontos em relevo na folha, de modo a permitir que pessoas cegas e com baixa visão pudessem fazer a leitura dos textos escritos a partir da decodificação tátil de pontos em relevo.

As letras do alfabeto latino passaram a ser representadas por células com seis pontos distribuídos em duas fileiras, com três pontos em cada lado da cela. A distinção entre as letras se dá pela relação da marcação dos pontos na cela Braille. Essa organização em relevo dos pontos na cela permite identificar o símbolo e relacioná-lo a uma letra ou símbolo.

O programa Braille Fácil (UFRJ, 2019) permite que a criação de uma impressão Braille seja uma tarefa muito rápida e fácil, podendo ser realizada com um mínimo de conhecimento da codificação Braille. O programa é composto de editor de textos integrador; editor gráfico para gráficos táteis; pré-visualizador da impressão Braille; impressor Braille 
automatizado; simulador de teclado Braille; utilitários para retoque em Braille; e utilitários para facilitar a digitação (UFRJ, 2019).

Outro aspecto relevante da produção do livro acessível foi a participação dos consultores na avaliação da obra. O retorno de cada consultor, tanto sobre o conteúdo, quanto sobre a forma que as versões acessíveis ganharam, foi de muita relevância, visto que ampliou o conhecimento em relação ao material e à técnica desejada. Em artigo relacionado à produção do livro $\mathrm{O}$ espelho mágico, um dos consultores destacou como, no processo de consultoria, recebia o material para avaliação e interagia com o material apresentado, considerando as demandas da autora. Nesse sentido, ele verificou quesitos como textura dos materiais utilizados, clareza das informações apresentadas através das diferenças entre os materiais e qualidade quanto à resistência, além de destacar sua contribuição quanto à importância do contraste entre as cores dos materiais, de modo a favorecer a fruição da obra por pessoas com baixa visão (MONTEIRO; FERNANDES, 2020).

Na produção do videolivro em Libras, a avaliação da consultora pontuou a dificuldade em visualizar os sinais feitos pelo intérprete, uma vez que a tela dele era pequena em relação à imagem, e em ler a legenda, pois essa estava passando muito rápido e em desacordo com o intérprete. Foi sugerido, então, que se aumentasse o quadro do intérprete e se diminuísse um pouco a imagem da ilustração para que o foco ficasse no intérprete.

Muitas vezes, elementos que passam despercebidos pelo autor podem saltar aos olhos do consultor. Foi o que aconteceu quanto à necessidade de se nomear a princesa, ressaltado pelas consultoras da causa feminina negra, do empoderamento e do reconhecimento da cultura e da beleza da mulher negra. Elas questionaram a necessidade de se nomear a Princesa, visto que o candidato à mão da princesa tinha nome, o qual era, várias vezes, mencionado ao longo da narrativa. As consultoras sugeriram um nome de matriz africana e, em consenso com o grupo, ficou acordado que a princesa se chamaria Gimbya, nome afro-nigeriano que significa princesa. Assim, a história passa a ter a princesa Gimbya, jovem negra empoderada e dona de si.

Os múltiplos formatos do livro precisavam ser acessados de forma fácil, prática e com pouco ou nenhum custo financeiro para o público. Por isso, foi feita a escolha de se colocar QR codes em uma das páginas finais do livro. Isso levou, então, à criação de um site eletrônico para armazenar e disponibilizar os múltiplos formatos do livro. 
Os livros em multiformatos, em geral, oferecem as adaptações em forma de CD que acompanham o livro. Isso acaba gerando a necessidade de os usuários terem um computador portátil com CD para acesso às mídias. A ideia de criar um site e disponibilizar os arquivos ao público, independente da aquisição do livro em tinta, vai ao encontro das novas formas de acesso ao material digital do brasileiro.

De acordo com os dados do IBGE de 2017 "a Internet era utilizada em $74,9 \%$ dos domicílios brasileiros, estando disseminada na maioria dos domicílios em todas as Grandes Regiões" (IBGE, 2017). Os dados ainda registram que o equipamento mais utilizado pelos brasileiros para acesso à internet é o telefone móvel celular, perfazendo um total de $98,7 \%$.

Os materiais hospedados no site estão livres para acesso e download por qualquer pessoa interessada. De acordo com o Capítulo IV - Das Limitações aos Direitos Autorais, Artigo 46, inciso l/d, da Lei de Direito Autoral, ou Lei no. 9.610, não constitui ofensa aos direitos autorais a reprodução "de obras literárias, artísticas ou científicas, para uso exclusivo de deficientes visuais, sempre que a reprodução, sem fins comerciais, seja feita mediante o sistema Braille" (BRASIL, 1998) ou quaisquer outros suportes que possibilitem acessibilidade para esse público. Sendo assim, o livre acesso aos materiais, mais que uma garantia à pessoa com deficiência, é um ato de respeito e inclusão.

A produção de obra literária acessível está ganhando gradativamente espaço no Brasil e no mundo. No Brasil, a escritora Claudia Werneck, que vem trabalhando com o tema da inclusão desde 1992 (CAVALCANTI, 2015), publicou em 2011 o livro Sonhos do Dia, com nove formatos diferentes. Em Portugal, a professora Célia Sousa, coordenadora do Projeto de Leitura Inclusiva Partilhada (PLIP), vem produzindo livros em multiformatos para leitores com necessidades específicas. Para Célia Sousa, os livros em multiformatos são livros impressos que reúnem, num único exemplar, texto aumentado, Braille, imagens em relevo (para crianças cegas ou com baixa visão) e pictogramas (para crianças com incapacidade intelectual ou limitações de outra natureza). Esses livros teriam códigos quick response $(Q R)$ que remetessem para um site onde os livros estariam disponíveis nas versões audiolivro e videolivro (SOUSA, 2018).

Os diferentes formatos disponibilizados buscam transpor as barreiras encontradas no formato convencional do livro impresso em tinta, possibilitando que outros formatos dentro do livro ou associados a ele permitam acesso a diferentes modos de leitura, visualização do texto e das imagens, manuseio e linguagem da obra literária. Esses 
http://dx.doi.org/10.5902/1984686X54666

formatos acessíveis teriam como finalidade aproximar a pessoa com deficiência ou necessidades específicas da obra de arte.

Em se tratando da obra literária, permitir acesso à narrativa, à trama que envolve os personagens, ao enredo, ao estilo do autor e da ilustração, bem como a outras características que potencializam a percepção estética, é possibilitar fruição ao maior número possível de pessoas. Os novos modelos sociais e legais destacam a importância da eliminação das barreiras e do reconhecimento da diversidade humana, bem como a especificidade de cada um diante dos diferentes materiais de comunicação. As dificuldades enfrentadas pelas pessoas com deficiência evidenciaram a necessidade de reformulação dos textos e seus formatos.

\section{Considerações finais}

Com base no que foi apresentado, conclui-se que o percurso de criação de obra literária acessível é multifacetado e requer diferentes atores em sua produção. Todavia, sua construção se torna de extrema relevância diante do contexto atual de inclusão que precisa garantir acesso de todos aos bens culturais, uma conquista relevante das pessoas com deficiência.

A produção de materiais acessíveis é um recurso novo para o público em geral. A produção de um material com tantos formatos pode parecer uma tarefa muito complicada, mas ela é possível de ser feita com poucos recursos financeiros, utilizando softwares gratuitos, como os programas de edição de áudio, hospedagem em sites gratuitos e programas como o Braille Fácil.

Ao fazer um livro acessível, pensando na integração dos materiais que fossem agradáveis a todos, passou-se da idealização de um trabalho com apenas um protagonista, para uma produção coletiva. Isso provocou o diálogo da autora com o ilustrador, do ilustrador com a autora, da autora com os consultores, dos consultores com a autora, da autora com a orientadora, da orientadora com a autora. Foi um processo lento, mas necessário, uma vez que não há que se falar de nada sobre nós sem nós.

A produção de um material literário comprometido com a proposta do Desenho Universal ensina que não basta fazer algo atraente para um público e, nesse percurso, criar barreiras para outros. É preciso criar materiais integrados que, em distintos formatos, tragam consigo um pouco da magia da história. Os diferentes formatos estão acessíveis 
http://dx.doi.org/10.5902/1984686X54666

para todo o público, que pode dispor do material de acordo com suas necessidades específicas, independente se essas são temporárias ou permanentes.

\section{Referências}

AMARANTE, Paulo; LIMA, Ricardo (Coord.) Nada sobre nós sem nós. Relatório final. / Oficina nacional / Coordenado por Paulo Amarante e Ricardo Lima. [Rio de Janeiro]: s.n., 2009. 125p. Disponível em: www.abrasme.org.br/arquivo/download?ID_ARQUIVO=3709. Acesso em: 21 ago. 2020.

Associação Brasileira de Normas Técnicas [ABNT]. NBR 15599. Acessibilidade: comunicação na prestação de serviços. Rio de Janeiro: ABNT, 2008. 39p.

AUDACITY. Editor e gravador de áudio gratuito. Página inicial. 2020. Disponível em: https://www.audacityteam.org/. Acesso em: 21 ago. 2020.

BORGES, José Antônio. DOSVOX - um novo horizonte para deficientes visuais. Revista Técnica do Instituto Benjamin Constant. n. 3, 1997.

BRASIL. Lei 13.146, de 06 de julho de 2015. Institui a Lei Brasileira de Inclusão da Pessoa com Deficiência (Estatuto da Pessoa com Deficiência). Brasília. Casa Civil. 2015. Disponível em: http://www.planalto.gov.br/ccivil_03/_Ato2015-2018/2015/Lei/L13146.htm. Acesso em: 26 jun. 2018.

BRASIL. MINISTÉRIO DA EDUCAÇÃO. Secretaria de Educação Continuada, Alfabetização, Diversidade e Inclusão. Diretoria de Políticas de Educação Especial. A consolidação da inclusão escolar no Brasil 2003 a 2016. Brasília: 2016. Disponível em: http://www.ufpb.br/cia/contents/manuais/a-consolidacao-da-inclusao-escolar-nobrasil-2003-a-2016.pdf. Acesso em: 12 jul. 2019.

BRASIL. Ministério da Educação. Secretaria de Educação Continuada, Alfabetização, Diversidade e Inclusão. Normas técnicas para a produção de textos em Braille / elaboração: DOS SANTOS, Fernanda Christina; OLIVEIRA, Regina Fátima Caldeira de. Brasília-DF, 2018a, 3a edição. 120p.

BRASIL. Ministério da Educação. Secretaria de Educação Continuada, Alfabetização, Diversidade e Inclusão. Grafia Braille para a Língua Portuguesa / Elaboração: DOS SANTOS, Fernanda Christina; DE OLIVEIRA, Regina Fátima Caldeira. Brasília-DF, 2018b, 3. ed. 95p.

CONNELL, Bettye Rose. et al. The principles of universal design. The Center for Universal Design. NC State University, 1997. Disponível em:

https://projects.ncsu.edu/ncsu/design/cud/about_ud/udprinciplestext.htm. Acesso em: 15 ago. 2020. 
FRANCO, Eliana Paes Cardoso; SILVA, Manoela Cristina Correia Carvalho.

Audiodescrição: breve passeio histórico. In: MOTTA, Lívia Maria Villela de Mello; FILHO, Paulo Romeu (Org.) Audiodescrição: transformando imagens em palavras. São Paulo: Secretaria dos Direitos da Pessoa com Deficiência do Estado de São Paulo. 2010.

Disponível em:

https://www.prefeitura.sp.gov.br/cidade/secretarias/upload/planejamento/prodam/arquivos/ Livro_Audiodescricao.pdf. Acesso em: 21 ago. 2020.

CASCUDO, Luís da Câmara. Contos tradicionais do Brasil. 13ํe. edão Paulo: Global, 2004.

CAVALCANTI, Luísa. Entrevista Claudia Werneck. Responsabilidade social. EDIÇÃO № 192. Maio 2015. Disponível em:

http://www.responsabilidadesocial.com/entrevista/claudia-werneck/. Acesso em: 12 jun. 2019

CUCA. Página inicial. 2020. Disponível em: https://www.cuca.bio.br/sub-o-que-e. Acesso em: 21 ago. 2020.

IBGE EDUCA. Conheça o Brasil - População pessoas com deficiência. 2010. Disponível em: https://educa.ibge.gov.br/jovens/conheca-o-brasil/populacao/20551pessoas-com-deficiencia.html. Acesso em: 11 ago. 2020.

IBGE. Censo Demográfico 2010 - Características Gerais da População, religião e pessoas com deficiência. IBGE, 2012. Disponível em:

https://biblioteca.ibge.gov.br/visualizacao/periodicos/94/cd_2010_religiao_deficiencia.pdf. Acesso em: 19 jul. 2019.

IBGE. Uso de Internet, televisão e celular no Brasil. 2017. Disponível em: https://educa.ibge.gov.br/criancas/brasil/2697-ie-ibge-educa/jovens/materiasespeciais/20787-uso-de-internet-televisao-e-celular-no-brasil.html. Acesso em: 29 mai. 2019.

KLIX, Tatiana. Torne suas aulas mais interativas com QR Codes. Revista Nova Escola, Blog Tecnologia na Educação. Fev. 2017. Disponível em:

https://novaescola.org.br/conteudo/4733/blog-tecnologia-torne-suas-aulas-maisinterativas-com-qr-code. Acesso em: 01 jun. 2019

KOCH, Ingedore Grunfeld Villaça. A coesão textual. 21. ed. São Paulo: Contexto, 2007.

$\mathrm{KOCH}$, Ingedore Grunfeld Villaça. O Texto e a construção dos sentidos. 9. ed. São Paulo; Contexto. 2010.

LEITE, Flavia Piva Almeida. A convenção sobre os direitos das pessoas com deficiência: amplitude conceitual. Revista de Direito Brasileira. Florianópolis, v. 3, n. 2, p. 31-53, jul/dez 2012 
LIMA, Francisco José de. Introdução aos estudos do roteiro para áudio-descrição: sugestões para a construção de um script anotado. In: Revista Brasileira de Tradução Visual. vol. 7. n. 7. 2011. Disponível em:

http://www.associadosdainclusao.com.br/enades2016/sites/all/themes/berry/documentos/0 8-introducao-ao-estudo-do-roteiro.pdf. Acesso em: 01 jun. 2019.

MONTEIRO, Felipe Vieira; FERNANDES, Edicléa Mascarenhas. A consultoria para um livro em multiformato no contexto educacional. RevistAleph. N. 10, 2020. Disponível em: https://periodicos.uff.br/revistaleph/article/view/42172/25230. Acesso em: 11 ago. 2020.

NUNES, Clarisse; MADUREIRA, Isabel. Desenho Universal para a Aprendizagem: Construindo práticas pedagógicas inclusivas. In: Da Investigação às Práticas, v. 5 , n. 2, p. 126-143, 2015. Disponível em: http://repositorio.ipl.pt/bitstream/10400.21/5211/1/84172-1-SM.pdf. Acesso em: 11 ago. 2020.

PINTO, Loide Leite Aragão. Criação de obra literária acessível: O Espelho Mágico. Universidade Federal do Rio de Janeiro. Monografia. Rio de Janeiro, 2019a. 104f.

PINTO, Loide Leite Aragão. O espelho mágico. In: Livros acessíveis: histórias em múltiplos formatos. Rio de Janeiro, 2019b. Disponível em:

https://www.loidearagao.com/oespelhomagico. Acesso em: 23 out. 2020.

SÁ, Elizabet Dias de; CAMPOS, Izilda Maria de; SILVA, Myriam Beatriz Campolina. Atendimento educacional especializado: deficiência visual. Brasília: Cromos, 2007. Disponível em: http://portal.mec.gov.br/seesp/arquivos/pdf/aee_dv.pdf. Acesso em: 22 de maio de 2019.

SANTA CATARINA. Secretaria de Estado da Educação. Fundação Catarinense de Educação Especial. Guia prático para adaptação em relevo/, Jussara da Silva (Coord.). São José: FCEE, 2011. Disponível em: https://www.fcee.sc.gov.br/informacoes/bibliotecavirtual/educacao-especial/cap/512-guia-pratico-de-apaptacao-em-relevo/file. Acesso em: 21 ago. 2020.

SILVA, Asafe Davi Cortina; FINATTO, Maria José Bocorny. Orientações básicas para a simplificação de um texto. Material em slides. Porto Alegre: UFRGS, 2018. Disponível em:

http://www.ufrgs.br/textecc/acessibilidade/files/COMO_SIMPLIFICAR_2018_Asafe_Mjose 2.pdf. Acesso em: 19 mai. 2019.

SOUSA, Célia. E se entrasse numa livraria e pedisse um livro MULTIFORMATO? III Encontro sobre inclusão em contexto escolar. Apresentação em slides, 2018.

Disponível em:

http://eventos.ccems.pt/inclusao/userfiles/File/Apresentacoes2018/CeliaSousa.pdf. Acesso em: 12 jun. 2019.

UFRJ. Braille Fácil 4.0. 2019. Disponível em: http://intervox.nce.ufrj.br/brfacil/. Acesso em: 11 de agosto de 2020. 
WAVOSAUR. Editor de áudio gratuito, 2020. Página inicial. Disponível em:

http://www.wavosaur.com. Acesso em: 21 ago. 2020.

\section{Correspondência}

\section{Loide Leite Aragão Pinto -}

Rua Álvares Lobo s/n, It 15 qd 06, Chacrinha, Duque de Caxias, Rio de Janeiro - Brasil. CEP: 25065-260

(c) (i) (9)

This work is licensed under a Creative Commons Attribution-NonCommercial 4.0 International (CC BY-NC 4.0) 